\title{
Characterization of Calcium Oxalate Biominerals in Some (Non-Cactaceae) Succulent Plant Species
}

\author{
Paula V. Monje and Enrique J. Baran* \\ Centro de Química Inorgánica (CEQUINOR, CONICET/UNLP), Facultad de Ciencias \\ Exactas, Universidad Nacional de La Plata, C. Correo 962, 1900 La Plata, Argentina. \\ E-mail: baran@yuimica.unlp.edu.ar \\ * Author for correspondence and reprint requests \\ Z. Naturforsch. 65 c, 429-432 (2010); received February 5, 2010
}

The water-accumulating leaves of crassulacean acid metabolism plants belonging to five different families were investigated for the presence of biominerals by infrared spectroscopic and microscopic analyses. Spectroscopic results revealed that the mineral present in succulent species of Agavaceae, Aizoaceae, and Asphodelaceae was calcium oxalate monohydrate (whewellite, $\mathrm{CaC}_{2} \mathrm{O}_{4} \cdot \mathrm{H}_{2} \mathrm{O}$ ). Crystals were predominantly found as raphides or solitary crystals of various morphologies. However, representative Crassulaceae members and a succulent species of Asteraceae did not show the presence of biominerals. Overall, these results suggest no correlation between calcium oxalate generation and crassulacean acid metabolism in succulent plants.

Key words: Succulent Plants, Biominerals, Whewellite, Crassulacean Acid Metabolism

\section{Introduction}

The succulent photosynthetic stem parenchyma of Cactaceae family members contains abundant calcium oxalate crystals. Whereas Opuntioideae (pad-like cacti) and Pereskioideae (ancestral cacti) species preferentially deposit calcium oxalate monohydrate $\left(\mathrm{CaC}_{2} \mathrm{O}_{4} \cdot \mathrm{H}_{2} \mathrm{O}\right.$, whewellite $)$, Cereoideae species (columnar cacti) show predominance of calcium oxalate dihydrate $\left(\mathrm{CaC}_{2} \mathrm{O}_{4}\right.$. $2 \mathrm{H}_{2} \mathrm{O}$, weddellite). In Cactaceae, crystals of calcium oxalate are found as druses, i.e. multi-crystal agglomerates with an overall spherical shape, regardless their chemical composition (Monje and Baran, 2002). Interestingly, the biomineralization of calcium oxalate in Cactaceae shows some exclusive features: 1 ) the content of calcium oxalate in photosynthetic tissues can reach up to $80-90 \%$ of the plants' dry weight: 2) most Cereoideae members show large diameter druses of highly pure and stable weddellite, a thermodynamically metastable form of calcium oxalate which is rarely found in living organisms under the form of a druse because it easily converts into whewellite: and 3) some species of cacti have shown co-existence of whewellite and weddellite in a single organism (Baran and Monje, 2008: Hartl et al., 2007: Malainine et al., 2003).
With the exception of some Pereskioideae species, all Cactaceae members are succulents, a diverse group of plants that store water in their leaves, stems and/or roots as an adaptive trait to arid soils, high temperature, and prolonged water deficit. Most succulent plants also display other water-saving features that include: 1) a reduced outer surface that confers the plants a typical columnar or spherical shape: 2) reduced or absent leaves and a stem adapted to perform photosynthesis: 3) a waxy, hairy or multi-layered epidermis with a reduced number of stomata, which are closed during the day and open during the night: 4) a type of photosynthesis known as crassulacean acid metabolism (CAM), which allows the fixation of carbon dioxide during the night thereby minimizing the loss of water through the open stomata (Bowyer and Leegwood, 1997). The relationship between CAM and calcium oxalate formation is at present unclear.

In this study, we investigated the presence of biominerals in CAM species not related to Cactaceae. Abundant crystals with different morphologies were isolated from the succulent photosynthetic tissues of all analysed succulent species of Agavaceae, Aizoaceae, and Asphodelaceae. Contrary to Cactaceae, the isolated crystalline material was predominantly found in the form of raphi- 
des, i.e. bundles of elongated needle-like crystals, and the spectroscopic analysis revealed that the biomineral present was always whewellite.

\section{Material and Methods}

\section{Plant material}

The succulent leaves of a number of representative CAM species were harvested from healthy and well-hydrated specimens growing under normal greenhouse conditions, regardless of the season and other environmental conditions. The plant material was kindly provided by the South Florida Cactus and Succulent Society (Miami, FL, USA).

\section{Crystal isolation and purification}

The crystalline material was isolated from fresh plant tissues following a previously described method (Monje and Baran, 2009). Briefly, the plant tissue was cut into thin slices using a razor blade and immersed in $6 \%$ sodium hypochlorite solution for $48 \mathrm{~h}$. The digested tissue sections were disrupted mechanically and filtered through sterile gauze. The filtered extract was allowed to decant for at least $30 \mathrm{~min}$ in a test tube or collected by low-speed centrifugation $(1,000 \mathrm{rpm}, 10 \mathrm{~min})$. The resulting pellet containing crystalline products was suspended in absolute ethanol, and the crystals were collected by inspection through a stereomicroscope. Crystals were repeatedly rinsed with ethanol until tissue debris was no longer evident. This procedure rendered crystalline samples consisting mainly of intact raphides and various quantities of solitary crystals of different morphologies, i.e. styloids and prismatic crystals.

\section{Infrared spectroscopy}

Purified samples were dried under a nitrogen flow before spectroscopic analysis. The IR spectra were obtained by means of a Bruker IFS 66 spectrophotometer in the spectral range between 4000 and $400 \mathrm{~cm}^{-1}$ using the $\mathrm{KBr}$ pellet technique ( $4 \mathrm{mg}$ of the powdered sample dispersed in $100 \mathrm{mg}$ of $\mathrm{KBr}$ ). The samples were determined as whewellite, by comparison with results from previous studies (Monje and Baran, 2002, 2009).

\section{Phase contrast microscopy}

For microscopic observations, freshly isolated crystals were suspended in water and mounted on glass slides for phase contrast microscopy on an Olympus IX-70 inverted microscope, using $10-40 \times$ dry objectives. Black and white digital pictures were processed and arranged for presentation using Adobe Photoshop 7.0 and Adobe Illustrator CS3.

\section{Results and Discussion}

In this study, we performed an infrared spectroscopic and microscopic analysis of the biomin-

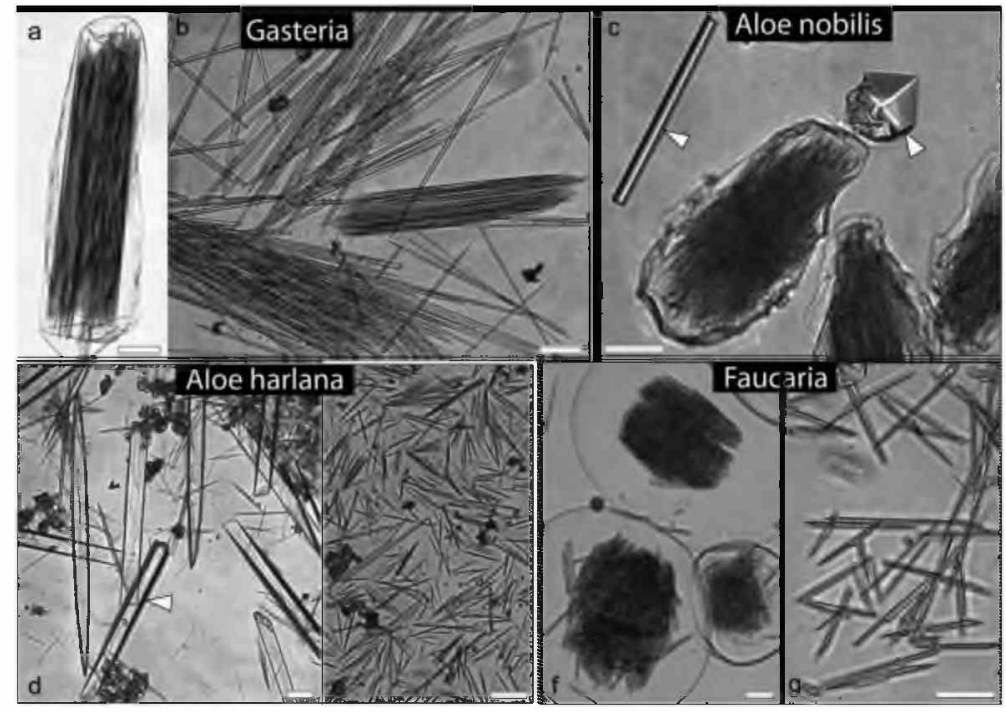

Fig. 1. Representative crystal shapes of calcium oxalate $\left(\mathrm{CaC}_{2} \mathrm{O}_{4} \cdot \mathrm{H}_{2} \mathrm{O}\right.$, whewcllite) from non-Cactaceac succulen species: (a, b) Gasteria liliputana; (c) Aloe nobilis: (d, c) A. harliana, and (i. g) Faucaria stomatium. Intact raphides still enclosed within the cell walls of the crystal-forming cells (a, c. and f) were typically found in the isolated preparations. Detailed images of the individual crystals that compose the raphides are shown in b. e, and $g$. Othcr crystal morphologics, e.g. styloids (d), and prismatic crystals (c and d. arrowheads) were less abundant but usually present in most of the analysed samples. Scale bars, $10 \mu \mathrm{m}$. 
Table I. Microscopic and IR-spectroscopic analysis of biominerals isolated from the leaves of non-Cactaceae succulent plants species.

\begin{tabular}{|c|c|c|c|c|}
\hline Family & Genus & Crystals $^{a}$ & Morphology & Chemical composition $^{b}$ \\
\hline \multirow[t]{2}{*}{ Agavaceae } & Agave parrasana & Yes, higly abundant & $\begin{array}{l}\text { Raphides (abundant) } \\
\text { Styloids (few) } \\
\text { Prismatic crystals (few) }\end{array}$ & Whewellite \\
\hline & Agave victoria & Yes, abundant & $\begin{array}{l}\text { Raphides (abundant) } \\
\text { Styloids (few) }\end{array}$ & Whewellite \\
\hline Aizoaceae & Faucaria stomatium & Yes, abundant & $\begin{array}{l}\text { Raphids (abundant) } \\
\text { Prismatic crystals (few) }\end{array}$ & Whewellite \\
\hline \multirow[t]{4}{*}{ Asphodelaceae } & Aloe nobilis & Yes, abundant & $\begin{array}{l}\text { Raphides (abundant) } \\
\text { Prismatic crystals (few) }\end{array}$ & Whewellite \\
\hline & Aloe harlana & Yes, abundant & Raphides (abundant) & Whewellite \\
\hline & Gasteria liliputana & Yes, abundant & Raphides (abundant) & Whewellite \\
\hline & Haworthia obtusa & Yes, abundant & Raphides (abundant) & Whewellite \\
\hline Asteraceae & Senecio citriformis & Not observed & & \\
\hline \multirow[t]{3}{*}{ Crassulaceae } & Sedum pachyphyllum & Not observed & & \\
\hline & $\begin{array}{l}\text { Graptopetalum } \\
\text { amethystimum }\end{array}$ & Not observed & & \\
\hline & Adromischus maculatus & Not observed & & \\
\hline
\end{tabular}

Microscopic observations.

Determined by IR spectroscopy.

erals present in the leaves of water-accumulating species of Agavaceae, Aizoaceae, Asphodelaceae. Crassulaceae, and Asteraceae (formerly named as Compositae). Infrared spectroscopy is a powerful tool for the investigation of the chemical composition of plant material (Baran. 2005) and we have used this methodology successfully in earlier investigations of plant biominerals, including calcium oxalates (e.g. Monje and Baran, 2002, 2009: Baran and Rolleri, 2009), magnesium oxalates (Monje and Baran, 2005) and silicon dioxide (e.g. Monje and Baran, 2000).

The results from the present study are summarized in Table I. Fig. 1 shows representative crystal shapes found in the isolated material of some of the investigated plants. Two important aspects emerge from the combined spectroscopic and microscopic analyses of this crystalline material: 1) all analyzed species of Agavaceae, Aizoaceae, and Asphodelaceae showed the presence of considerable quantities of whewellite, whereas no traces of weddellite or other biominerals (e.g. silicon dioxide) were detected: and 2) whewellite was found mainly in the form of raphides, whereas styloids and/or single prismatic crystals were present to a much lesser extent in all crystal-forming species. No druses were observed. Importantly, spectroscopic analyses did not reveal the presence of crystalline material in the leaves of three selected species of Crassulaceae and a succulent species of Asteraceae. The absence of crystals in these species was confirmed by microscopic observations of live tissue sections.

Despite the widespread occurrence of calcium oxalates in the plant kingdom, limited information has been given on the presence of calcium oxalates in succulent species displaying CAM, with the exception of Cactaceae (Rivera and Smith, 1979: Monje and Baran, 2002: Hartl et al. 2007: Baran and Monje, 2008). The results from the present study indicate that calcium oxalates are also abundant in the succulent tissues of Agavaceae, Asphodelaceae, and Aizoaceae species. Consistent with our findings. two species of $A g a$ ve, A. tequilana and $A$. americana, and an undetermined species of Aloe were shown to deposit raphides of calcium oxalate (Wattendorf, 1976: Ishii, 1992: Tadokoro et al., 2005). The presence of abundant needle-like crystals in the leaves of A. tequilana was linked to the effects of this plant, irritant contact dermatitis, in workers of Agave plantations and tequila distilleries (Salinas et al. 2001). In addition, raphide crystals were shown to be a conserved feature of the leaf epidermis of succulent Conophytum species (Aizoaceae): however, the chemical composition of these crystals was not determined. The presence of raphides was also described in the halophyte Mesembryan- 
themum crystallinum (Aizoaceae), a plant mode1 for the study of CAM (Jou et al., 2007).

Interestingly, all crystal-forming species analyzed in this study formed whewellite as either raphides or single elongated crystals, which clearly contrast with the presence of druses of whewellite in Cactaceae. Indeed, the occurrence of raphides and other needle-like crystal morphologies is rare in this plant family (Hartl et al., 2007). The observed diversity of crystal morphologies for a single biomineral is in agreement with the longstanding observation that whewellite may display a wide variety of crystal shapes, depending on the species and the location in the plant body (Webb, 1999).

In spite of the abundance of calcium oxalates in some xerophytic angiosperma, not all CAM species analyzed in this study showed the presence of calcium oxalates, including members of the Crassulaceae family. Indeed, the presence of calcium oxalates in Crassulaceae seems to be rare and, to the best of our knowledge, crystals of this

Baran E. J. (2005), Applications of vibrational spectroscopy to the investigation of plant material. In: Advances in Plant Physiology, Vol. 8 (Hemantaranjan H., ed.). Scientific Publishers, Jodhpur, pp. 365-392.

Baran E. J. and Monje P. V. (2008), Oxalate biominerals. In: Metal Ions in Life Sciences, Vol. 4 (Sigel A., Sigel H., and Sigel R. K. O., eds.). J. Wiley, Chichester, pp. $219-254$.

Baran E. J. and Rolleri C. H. (2009), IR-spectroscopic characterization of biominerals in the marattiaceaeus ferns. Rev. Bras. Bot. (in press).

Bowyer J. R. and Leegwood R. C. (1997), Photosynthesis. In: Plant Biochemistry (Dey P. M. and Harborne J. B., eds.). Academic Press, San Diego, pp. 49-110.

Hartl W. P., Klapper H., Barbier B., Ensikat H. J., Dronskowski R., Müller P., Ostendorp G., Tye A., Bauer R., and Barthlott W. (2007), Diversity of calcium oxalate crystals in Cactaceae. Can J. Bot. 85, 501-517.

Ishii Y. (1992), Needle crystal of calcium-oxalate monohydrate found in plant. J. Electron Microsc. 41, $53-56$.

Jou Y., Wang Y. L., and Yen H. C. E. (2007), Vacuolar acidity, protein profile, and crystal composition of epidermal bladder cells of the halophyte Mesembryanthemum crystallinum. Funct. Plant Biol. 34, 353-359.

Malainine M. E., Dufresne A., Dupeyre D., Vignon M. R., and Mahrouz M. (2003). First evidence for the presence of weddellite crystallites in Opuntia ficus indica parenchyma. Z. Naturforsch. 58c, 812-816. biomineral have not been chemically characterized in members of this plant family. Although the connection between calcium oxalate biomineralization and water stress adaptation, including CAM, remains obscure, it becomes now evident that calcium oxalate generation may not represent a simple end product of CAM in the photosynthetic tissues of water-accumulating plants. Overall, our results suggest that calcium oxalate precipitation in Cactaceae may not be related to the acquisition of a succulent or CAM physiotype in this plant family.

\section{Acknowledgements}

This work was supported by the Universidad Nacional de La Plata (UNLP) and the Consejo Nacional de Investigaciones Científicas y Técnicas de la República Argentina (CONICET). E. J. $B$. is a member of the Research Career of this organism. We are grateful to the South Florida Cactus and Succulent Society for providing all plant specimens analyzed in this study.

Monje P. V. and Baran E. J. (2000), First evidences of the bioaccumulation of $\alpha$-quartz in a Cactaceae. J. Plant Physiol. 157, 457-460.

Monje P. V. and Baran E. J. (2002), Characterization of calcium oxalates generated as biominerals in cacti. Plant Physiol. 128, 707-713.

Monje P. V. and Baran E. J. (2005), Evidence of the formation of glushinskite as a biomineral in a Cactaceae species. Phytochemistry 66, 611-614.

Monje P. V. and Baran E. J. (2009), Characterization of calcium oxalate biominerals in Pereskia species (Cactaceae). Z. Naturforsch. 64c, 763-766.

Rivera E. R. and Smith B. N. (1979), Crystal morphology and ${ }^{13}$ carbon $/{ }^{12}$ carbon composition of solid oxalate in cacti. Plant Physiol. 64, 966-970.

Salinas M. L., Ogura T., and Soffchi L. (2001), Irritant contact dermatitis caused by needle-like calcium oxalate crystals, raphides in Agave tequilana among workers in tequila distilleries and agave plantations. Cont. Dermat. 44, 94-96.

Tadokoro M., Ozawa Y., Mitsumi M., Toriumi K., and Ogura T. (2005), Raphide crystal structure in Agave tequilana determined by X-ray originating from synchrotron radiation. Chem. Lett. 34, 236-237.

Wattendorff J. (1976), 3Rd type of raphide crystal in plant kingdom - 6-sided raphides with laminated sheets in Agave americana L. Planta 130, 303-311.

Webb M. A. (1999), Cell-mediated crystallization of calcium oxalate in plants. Plant Cell 11, 751-761. 